Barte, J.C.M., Hendriks, M.R.C., Rutten, G., Veenhof, C., Bemelmans, W.J.E. Implementation of the 'BeweegKuur' in practice: utilization of care of a lifestyle intervention in the Netherlands.

\begin{tabular}{|l|l|}
\hline $\begin{array}{l}\text { Postprint } \\
\text { Version }\end{array}$ & 1.0 \\
\hline Journal website & http://www.tandfonline.com/doi/abs/10.1080/14635240.2014.912444 \\
\hline Pubmed link & \\
\hline DOI & $10.1080 / 14635240.2014 .912444$ \\
\hline
\end{tabular}

This is a NIVEL certified Post Print, more info at http://www.nivel.eu

\title{
Implementation of the 'BeweegKuur' in practice: utilization of care of a lifestyle intervention in the Netherlands
}

\author{
JEROEN C.M. BARTE ${ }^{A B^{*}}$, MARIKE R.C. HENDRIKS ${ }^{\mathrm{C}}$, GEERT RUTTEN ${ }^{\mathrm{D}}$, CINDY VEENHOF ${ }^{\mathrm{E}}$ \& \\ WANDA J.E. BEMELMANS ${ }^{\mathrm{A}}$
}

\begin{abstract}
This study investigates the delivered care in a multidisciplinary lifestyle intervention by dieticians and physiotherapists compared to the protocol of this intervention. Participants with a body mass index (BMI) between 25 and $40 \mathrm{~kg}$ $\mathrm{m}^{-2}$ were divided over three different programs depending on their BMI and comorbidities. All these programs consisted of individual and group sessions with the dietician, while care by the physiotherapist differed by program. The dieticians and physiotherapists of 30 locations were contacted to provide data about health care use within the intervention from their health records. Data of 379 participants were available and showed that group sessions by dieticians were often not attended. Care by the physiotherapist was delivered according to the protocol to a larger extent. An average of $43-93 \%$ of the sessions was attended. The level of attendance is comparable to other interventions, but especially attendance at group sessions with dieticians should be improved.
\end{abstract}

\section{INTRODUCTION}

In the Netherlands, a multidisciplinary lifestyle intervention has been developed and enrolled throughout the country. This 1-year intervention, called 'BeweegKuur', promotes physical activity and a healthy diet, and is guided by the general practitioner, lifestyle advisor, physical therapist, and dietician (Berendsen et al. 2011). Participants were referred to a lifestyle advisor by one of the health care providers. The lifestyle advisor gave individual counseling and referred participants to physical therapist and dietician for assistance in their behavior change. The intervention targets patients with a high weight-related health risk and aims to improve physical activity and dietary behavior and thereby reduce health risks. Lifestyle interventions such as 'BeweegKuur' have shown to be effective (Barte et al. 2010 Bogers et al. 2010; Curioni and Lourenco 2005; Wu et al. 2009). However, besides investigating the effects of lifestyle interventions in a research setting, 
Barte, J.C.M., Hendriks, M.R.C., Rutten, G., Veenhof, C., Bemelmans, W.J.E. Implementation of the 'BeweegKuur' in practice: utilization of care of a lifestyle intervention in the Netherlands.

International Journal of Health Promotion and Education: 2014, 52(4), 222-228

research is needed on the implementation of these interventions. Implementation refers to the extent in which the intervention is delivered as intended (Glasgow, Vogt, and Boles 1999). By investigating this in a real practice setting, more insight can be gained about whether the effects as shown in a research setting can also be achieved when executing the intervention in practice. Furthermore, research on implementation can help to improve the application of the intervention, generate evidence as a basis on which to make adjustments if required, and determine costs and interpret the effects. Nevertheless, the extent in which the protocol is delivered as intended is not often investigated in lifestyle interventions (Akers, Estabrooks, and Davy 2010). Therefore, we investigate the participants' utilization of care delivered by dieticians and physiotherapists within the 'BeweegKuur' intervention in the Netherlands compared to the intervention protocol.

\section{INTERVENTION THE 'BEWEEGKUUR'}

Three different programs are offered to patients depending on their health risk. Programs are similar in lifestyle advice and dietician's care, but the amount of support by physiotherapists differs. Patients with a body mass index (BMI) of 25-35 $\mathrm{kg} \mathrm{m}^{-2}$ without comorbidities are offered an independent exercise program and patients with a BMI of 25-35 $\mathrm{kg} \mathrm{m}^{-2}$ with comorbidities or a BMI of 35-40 $\mathrm{kg} \mathrm{m}^{-2}$ are offered the start-up exercise program or the supervised exercise program (Berendsen et al. 2011).

The intervention protocol for care by dieticians and physiotherapists is described in Table 1. It indicates three individual contact sessions with a dietician to provide an individual diet advice and to evaluate progress. Furthermore, the protocol states seven group sessions of 90 min by a dietician for social support, to change behavior, and to improve skills. The protocol for physiotherapists differs for the distinct programs in the 'BeweegKuur.' The independent exercise program contains only one visit to the physiotherapist to check the participants' physical abilities and to receive advice on their exercise plan. The start-up exercise program contains an individual intake to gather information, an individual session to create an exercise plan, and four follow-up sessions (possibly in groups) led by the physiotherapist to discuss progress. The supervised exercise program offers an individual intake, an individual session to create an exercise plan, two individual training sessions, 24 group-training sessions, and three individual follow-up sessions to discuss progress and adjust exercise plan. If necessary, the physiotherapist could extend the supervised exercise program with one individual session and eight group-training sessions. More information on the intervention can be found elsewhere (Berendsen et al. 2011).

\section{[TABLE 1]}

\section{METHODS}

\section{Participants and measurements}

Different health care providers from 30 locations that implemented the

'BeweegKuur' included patients in the intervention after inviting them during regular consultations or recruiting them actively from their registrations. Locations consisted 
Barte, J.C.M., Hendriks, M.R.C., Rutten, G., Veenhof, C., Bemelmans, W.J.E. Implementation of the 'BeweegKuur' in practice: utilization of care of a lifestyle intervention in the Netherlands.

International Journal of Health Promotion and Education: 2014, 52(4), 222-228

of one or more general practices and the collaborating dieticians and niver physiotherapists. The inclusion period was between July 2010 and October 2011, and all participants signed an informed consent including permission for the use of data of intervention-related health care use with dietician and physiotherapist. For every selected location, the dietician and physiotherapist were contacted by phone and e-mail to provide registered data of health care use within the 'BeweegKuur' from the health records every location is obliged to keep for daily practice. Thereafter, they received a standardized form to complete with the required data, but they were free to provide data in any other format if more convenient for them. All health care providers were given at least 6 weeks to fulfill our request and were reminded if they did not respond. The health care providers were asked to provide per participant the number of individual and group sessions, duration of these sessions, and group sizes. In addition, the health care providers were asked to indicate whether the participant closed the 'BeweegKuur' as a whole or a component of the intervention (i.e. physiotherapist sessions, individual dietitian sessions, or group dietitian sessions). A 'BeweegKuur' component was considered as closed when the participant finished (i.e. completed or stopped) this part of the intervention and the participant was not expected to attend further sessions within the 'BeweegKuur' context.

Participants were included in our analyses when their dietician or physiotherapist provided data on their health care use within the 'BeweegKuur'. In addition, participants were only taken into account for the 'BeweegKuur' components they closed, i.e., the individual sessions with the dietician, the group sessions with the dietician, or the sessions with the physiotherapist.

\section{Analyses}

Descriptive statistics were performed to describe the number, duration, and group size of the dietician and physiotherapy sessions.

\section{RESULTS}

\section{Study sample}

In total, the 30 locations included 572 participants in the intervention (58 in the independent exercise program, 275 in the start-up exercise program, and 239 in the supervised exercise program). We were able to contact 28 physiotherapists and 25 dieticians, of whom 12 physiotherapists and 18 dieticians provided the requested data. The main reason for not providing data was the lack of time to retrieve the data. Data of 379 participants were eligible for inclusion in one of our analyses; 218 participants closed the individual sessions by the dietician, 277 participants closed the group sessions by the dietician, and 205 participants closed sessions by the physiotherapist (14 in the independent exercise program, 100 in the start-up exercise program, and 91 in the supervised exercise program). Mean age of the participants was 53.5 years, and $67 \%$ were female.

\section{Delivered care by dietician}

The first part of Table 1 shows the delivered care by the dieticians. The number of individual sessions with the dietician was on average 2.3 with an average duration of 
Barte, J.C.M., Hendriks, M.R.C., Rutten, G., Veenhof, C., Bemelmans, W.J.E. Implementation of the 'BeweegKuur' in practice: utilization of care of a lifestyle intervention in the Netherlands.

International Journal of Health Promotion and Education: 2014, 52(4), 222-228

49 min. Some participants (14\%) did not have any individual sessions with the dietician, and almost one out of three participants had only one individual session. About 25\% of the participants received more than three individual sessions (mostly 4-6 sessions).

Most dieticians offered seven group sessions according to the protocol, but two dieticians indicated that they did not offer group sessions and two dieticians offered five or six group sessions. In total, 33\% of the participants did not attend any group sessions led by the dietician. On average, participants visited three group sessions, which mostly had a duration of $90 \mathrm{~min}(67 \%)$. The mean number of participants at a group session was 9.1 (median was 9).

\section{Delivered care by physiotherapist}

The second part of Table 1 shows the care as delivered by the physiotherapists for the start-up exercise program. Participants in the start-up exercise program had on average 3.9 individual sessions. Almost all participants had one (24\%) or more (71\%) individual contact sessions. Some physiotherapists chose to offer group sessions to the participants, but the majority of the participants (75\%) did not have any of these sessions. Most of the participants (76\%) received three to seven contact sessions, which roughly corresponds with the six sessions prescribed in their protocol (Table 2).

\section{[TABLE 2]}

In addition, Table 1 shows the care as delivered by the physiotherapists for the supervised exercise program. Participants in the supervised exercise program had on average 2.6 individual sessions of 41 min with a physiotherapist and $96 \%$ of the participants had at least one individual session. Group sessions were attended by $83 \%$ of the participants in the supervised exercise program, and on average, 17.8 sessions of 60 min were attended. The mean group size during these group sessions was 5.2 (median was 5). Fourty-eight percent of these participants received care that corresponds roughly with the protocol, and $25 \%$ received slightly too few sessions (Table 2).

For the independent exercise program, data of only 14 participants were available. They had a mean number of 1.9 individual sessions and 5.4 group sessions. These participants had often more sessions than stated in their protocol (Table 2).

\section{Discussion}

This study investigates the delivered care by dieticians and physiotherapists within the intervention 'BeweegKuur' compared to the intervention protocol. It shows that individual care by the dietician was only a small component of the intervention. Group sessions by dieticians were often not attended, which could for a small part be explained by the two (out of 18) dieticians who did not offer these sessions. Care by the physiotherapist for participants in the start-up exercise program was delivered as in the protocol to a large extent. Participants in the supervised exercise program attended less than half of the individual sessions as stated in the protocol, but a majority of the number of group sessions in the protocol was attended. For the 
Barte, J.C.M., Hendriks, M.R.C., Rutten, G., Veenhof, C., Bemelmans, W.J.E. Implementation of the 'BeweegKuur' in practice: utilization of care of a lifestyle intervention in the Netherlands. International Journal of Health Promotion and Education: 2014, 52(4), 222-228

independent exercise program, unfortunately not enough information was available to draw conclusions.

An extensive review on implementation and the influence on program outcomes showed that it is unrealistic to expect perfect or near-perfect implementation because only a few studies had an attendance of more than 80\% (Durlak and DuPre 2008). For the current study, $77 \%$ of the dietician's individual sessions, $43 \%$ of the dietician's group sessions, $93 \%$ of the physiotherapy sessions in the start-up exercise program, and $68 \%$ of the physiotherapy sessions in the supervised exercise program were attended on average compared to the protocol. These results are comparable to other lifestyle interventions in which 31-75\% of the sessions were attended (Akers, Estabrooks, and Davy 2010).

It is noteworthy that for some parts of the program, a number of individuals received more sessions than stated in the protocol. For example, one out of four participants had more individual sessions with a dietician than stated in the protocol. Also, despite the low numbers in the independent exercise program, it is remarkable that most participants received more exercise sessions than the one as described in the protocol. These findings emphasize the need for implementation research of lifestyle interventions to show the care that patients received in reality. Furthermore, these results underline that the protocol of the 'BeweegKuur' is seen as a guideline that is fluid to the individual needs of the participants.

Because the level of implementation of a program is an important determinant of program outcomes and better implementation may lead to stronger benefits for participants (Durlak and DuPre 2008), the low attendance with dietician's group sessions needs improvement. During contact on data provision, a number of dieticians indicated that the two main reasons of participants for not attending group sessions were that the timing of the sessions was not convenient for the participants and that the content of the sessions did not add any knowledge beside the individual sessions. For further implementation, dieticians should explain the participants that the main goals of the group sessions are social support and improving skills instead of information provision. Furthermore, dieticians in the 'BeweegKuur' and health care providers in other interventions should consult the participants for the most appropriate time for their group sessions. This emphasizes the importance of a clear communication and shared decision-making, which are established as factors affecting implementation (Durlak and DuPre 2008).

A few limitations of this evaluation should be mentioned. Despite the large sample of participants from general practices all over the Netherlands, the response of the physiotherapists was lower than the response of the dieticians (43\% vs. 72\%). This lower response for physiotherapists could indicate a potential selection bias (i.e. physiotherapists with poorer implementation may be less likely to provide data). The main reason for not providing data was that the health care providers had a lack of time to cooperate; however, a potential selection bias cannot be completely ruled out. The low response of physiotherapists also led to insufficient data on the independent exercise program. Furthermore, registered data were provided by health care providers. These data may be slightly less reliable than observational data, but were preferred above patients' recall. Also, no large bias is expected because health care providers were asked to retrieve data on patient level from the registered health records instead of providing summarized data. 
Barte, J.C.M., Hendriks, M.R.C., Rutten, G., Veenhof, C., Bemelmans, W.J.E. Implementation of the 'BeweegKuur' in practice: utilization of care of a lifestyle intervention in the Netherlands. International Journal of Health Promotion and Education: 2014, 52(4), 222-228

In conclusion, on average, fewer sessions were delivered than prescribed in the protocol. This is comparable to other interventions, but especially the group sessions with dieticians were attended fewer than stated in the protocol. Further research on the effectiveness of the 'BeweegKuur' has to reveal the need for improvement of the implementation or changes in the protocol.

\section{Conflict of interest}

The authors declare no conflict of interest.

\section{Notes}

${ }^{a}$ The protocol describes that the four follow-up sessions in the start-up exercise program can be provided individually or in groups. This means that, in total, individuals are provided two individual sessions and four group sessions or six individual sessions and zero group sessions.

${ }^{\mathrm{a}}$ This program contains one session by physiotherapist according to the protocol.

${ }^{b}$ This program contains six sessions by physiotherapist according to the protocol.

${ }^{\mathrm{c}}$ This program contains 31 sessions by physiotherapist according to the protocol.

\section{REFERENCES}

1. Akers, J. D., P. A.Estabrooks, and B. M.Davy. 2010. "Translational Research: Bridging the Gap Between Long-Term Weight Loss Maintenance Research and Practice." Journal of the American Dietetic Association110 (10): 1511-1522.

2. Barte, J. C. M., N. C. W.Ter Bogt, R. P.Bogers, P. J.Teixeira, B.Blissmer, T. A.Mori, and W. J. E.Bemelmans. 2010. "Maintenance of Weight Loss After Lifestyle Interventions for Overweight and Obesity, A Systematic Review." Obesity Reviews11 (12): 899-906.

3. Berendsen, B. A., M. R.Hendriks, E. A.Verhagen, N. C.Schaper, S. P.Kremers, and H. H.Savelberg. 2011. "Effectiveness and Cost-Effectiveness of 'BeweegKuur', A Combined Lifestyle Intervention in the Netherlands: Rationale, Design and Methods of a Randomized Controlled Trial." BMC Public Health11: 815-823.

4. Bogers, R. P., J. C. M.Barte, C. M. A.Schipper, S. M. C.Vijgen, E. L.de Hollander, L.Tariq, I. E. J.Milder, and W. J. E.Bemelmans. 2010. "Relationship Between Costs of Lifestyle Interventions and Weight Loss in Overweight Adults." Obesity Reviews11 (1): 51-61.

5. Curioni, C. C., and P. M.Lourenco. 2005. "Long-Term Weight Loss After Diet and Exercise: A Systematic Review." International Journal of Obesity (London)29 (10): 11681174.

6. Durlak, J. A., and E. P.DuPre. 2008. "Implementation Matters: A Review of Research on the Influence of Implementation on Program Outcomes and the Factors Affecting Implementation." American Journal of Community Psychology41 (3-4): 327-350.

7. Glasgow, R. E., T. M.Vogt, and S. M.Boles. 1999. "Evaluating the Public Health Impact of Health Promotion Interventions: The RE-AIM Framework." American Journal of Public Health89 (9): 1322-1327.

8. Wu, T., X.Gao, M.Chen, and R. M.van Dam. 2009. "Long-Term Effectiveness of Diet-PlusExercise Interventions vs. Diet-Only Interventions for Weight Loss: A Meta-Analysis." Obesity Reviews10 (3): 313-323.

\section{TABLES}


Table 1. Intervention protocol and delivered care by dietician and physiotherapist.

\begin{tabular}{|c|c|c|c|c|c|c|c|}
\hline \multirow[b]{2}{*}{$\begin{array}{l}\text { Health care } \\
\text { provider }\end{array}$} & \multirow[b]{2}{*}{$\begin{array}{c}\text { Type } \\
\text { 'BeweegKuur' } \\
\text { program }\end{array}$} & \multicolumn{3}{|c|}{ Protocol } & \multicolumn{3}{|c|}{ Delivered care } \\
\hline & & Sessions & Number & Time (min) & $\begin{array}{l}\text { Mean number } \\
\text { of sessions } \\
(N, \mathrm{SD} \text {, range) }\end{array}$ & $\begin{array}{l}\text { Mean duration } \\
(N, \mathrm{SD} \text {, range })\end{array}$ & $\begin{array}{l}\text { Group size } \\
(N, \mathrm{SD}, \text { range })\end{array}$ \\
\hline \multirow[t]{5}{*}{ Dietician } & \multirow[t]{5}{*}{ All programs } & Individual intake & 1 & No guideline & & & \\
\hline & & $\begin{array}{l}\text { Individual guidance } \\
\text { and follow-up }\end{array}$ & 2 & No guideline & & & \\
\hline & & Group sessions & 7 & 90 & & & \\
\hline & & Total individual sessions & 3 & & $2.3(218,2.0,0-10)$ & $49 \min (188,24,15-105)$ & Individual \\
\hline & & Total group sessions & 7 & & $3.0(277,2.6,0-7)$ & $92 \min (186,16,60-120)$ & $9.1(95,2.4,3-13)$ \\
\hline \multirow[t]{15}{*}{ Physiotherapist } & \multirow{3}{*}{$\begin{array}{c}\text { Independent } \\
\text { exercise } \\
\text { program }\end{array}$} & Individual intake and advice & 1 & \multirow[t]{3}{*}{45} & & & \\
\hline & & Total individual sessions & 1 & & $1.9(14,2.1,0-6)$ & $40 \min (10,7,30-50)$ & Individual \\
\hline & & Total group sessions & 0 & & $5.4(14,9.1,0-24)$ & $57 \min (5,7,45-60)$ & $4.8(5,0.4,4-5)$ \\
\hline & \multirow{5}{*}{$\begin{array}{l}\text { Start-up } \\
\text { exercise } \\
\text { program }\end{array}$} & Individual intake and advice & 1 & 45 & & & \\
\hline & & Individual guidance & 1 & 30 & & & \\
\hline & & $\begin{array}{l}\text { Follow-up sessions } \\
\text { (group or individual) }\end{array}$ & 4 & 30 & & & \\
\hline & & Total individual sessions & 2 or $6^{\mathrm{a}}$ & & $3.9(100,2.4,0-12)$ & $36 \min (95,8,30-60)$ & Individual \\
\hline & & Total group sessions & 0 or $4^{\mathrm{a}}$ & & $1.7(100,4.5,0-24)$ & $79 \min (25,29,60-120)$ & $5.5(25,2.0,3-8)$ \\
\hline & \multirow{7}{*}{$\begin{array}{c}\text { Supervised } \\
\text { exercise } \\
\text { program }\end{array}$} & Individual intake and advice & 1 & 45 & & & \\
\hline & & Individual guidance & 1 & 30 & & & \\
\hline & & Individual training sessions & 2 & 30 & & & \\
\hline & & Group sessions & 24 & 60 & & & \\
\hline & & Individual follow-up & 3 & 30 & & & \\
\hline & & Total individual sessions & 7 & & $2.6(91,1.4,0-6)$ & $41 \min (87,11,30-60)$ & Individual \\
\hline & & Total group sessions & 24 & & $17.8(91,9.7,0-33)$ & $60 \min (76,0,60-60)$ & $5.2(62,0.9,4-7)$ \\
\hline
\end{tabular}

${ }^{a}$ The protocol describes that the four follow-up sessions in the start-up exercise program can be provided individually or in groups. This means that, in total, individuals are provided two individual sessions and four group sessions or six individual sessions and zero group sessions. 
Barte, J.C.M., Hendriks, M.R.C., Rutten, G., Veenhof, C., Bemelmans, W.J.E. Implementation of the 'BeweegKuur' in practice: utilization of care of a lifestyle intervention in the Netherlands.

International Journal of Health Promotion and Education: 2014, 52(4), 222-228

Table 2. Percentage participants per program that attended a total number of physiotherapy sessions that corresponds with the different protocols.

\begin{tabular}{|c|c|c|c|}
\hline $\begin{array}{l}\text { Total number of } \\
\text { physiotherapy sessions } \\
\text { attended (individual } \\
\text { and group) }\end{array}$ & $\begin{array}{c}\text { Percentage of } \\
\text { participants in the } \\
\text { independent exercise } \\
\text { program }(\%)^{\mathrm{a}}\end{array}$ & $\begin{array}{l}\text { Percentage of } \\
\text { participants in the } \\
\text { start-up exercise } \\
\text { program }(\%)^{\mathrm{b}}\end{array}$ & $\begin{array}{l}\text { Percentage of } \\
\text { participants in the } \\
\text { supervised exercise } \\
\text { program }(\%)^{\mathrm{c}}\end{array}$ \\
\hline 0 & 21 & 4 & 4 \\
\hline $1-2$ & 21 & 8 & 7 \\
\hline $3-7$ & 36 & 76 & 7 \\
\hline $8-15$ & 0 & 9 & 9 \\
\hline $16-23$ & 14 & 0 & 25 \\
\hline 24 or more & 7 & 3 & 48 \\
\hline
\end{tabular}

${ }^{\mathrm{a}}$ This program contains one session by physiotherapist according to the protocol.

${ }^{\mathrm{b}}$ This program contains six sessions by physiotherapist according to the protocol.

${ }^{\mathrm{c}}$ This program contains 31 sessions by physiotherapist according to the protocol. 